\title{
Determination of Heavy Metals Concentration in Traditional Herbs Commonly Consumed in the United Arab Emirates
}

\author{
Rania Dghaim, Safa Al Khatib, Husna Rasool, and Munawwar Ali Khan \\ Department of Natural Science and Public Health, College of Sustainability Sciences and Humanities, \\ Zayed University, P.O. Box 19282, Dubai, UAE \\ Correspondence should be addressed to Rania Dghaim; rania.dghaim@zu.ac.ae
}

Received 21 February 2015; Accepted 15 April 2015

Academic Editor: Pam R. Factor-Litvak

Copyright (C) 2015 Rania Dghaim et al. This is an open access article distributed under the Creative Commons Attribution License, which permits unrestricted use, distribution, and reproduction in any medium, provided the original work is properly cited.

\begin{abstract}
Herbs are extensively consumed in the United Arab Emirates for their flavoring and medicinal properties. This study aimed at determining the concentration of heavy metals in selected traditional herbs consumed in the United Arab Emirates (UAE). A total of 81 samples of seven herbs, parsley (Petroselinum crispum), basil (Ocimum basilicum), sage (Salvia officinalis), oregano (Origanum vulgare), mint (Mentha spicata), thyme (Thymus vulgaris), and chamomile (Matricaria chamomilla), were purchased from the local market in Dubai and analyzed for their cadmium, lead, copper, iron, and zinc contents. Microwave-assisted digestion was applied for the dissolution of the samples and heavy metals concentration was determined using Atomic Absorption Spectrometry (AAS). Metals were found to be present in varied concentrations in the herb samples. The concentration ranges were found as follows: less than $0.1-1.11 \mathrm{mg} \cdot \mathrm{kg}^{-1}$ for cadmium, less than $1.0-23.52 \mathrm{mg} \cdot \mathrm{kg}^{-1}$ for lead, $1.44-156.24 \mathrm{mg} \cdot \mathrm{kg}^{-1}$ for copper, $12.65-146.67 \mathrm{mg} \cdot \mathrm{kg}^{-1}$ for zinc, and $81.25-1101.22 \mathrm{mg} \cdot \mathrm{kg}^{-1}$ for iron. The findings of the study suggest that most of the analyzed herbs contained unsafe levels of heavy metals that exceeded the World Health Organization (WHO) permissible limits (PL).
\end{abstract}

\section{Introduction}

Herbal remedies are widely used for the treatment of various illnesses. They often contain highly active pharmacological components including minerals and trace metals [1]. Herbal plants represent an important class of various traditional medicine systems and, in recent years, they are increasingly used in the primary health care intervention in both developed and developing countries. According to World Health Organization (WHO) estimates, nearly $70-80 \%$ of the world population still primarily relies on nonconventional medications, mostly derived from herbal plants $[2,3]$. The United Arab Emirates (UAE) is known for its rich tradition of herbal medicine, and the Emirati population is quite familiar with the medicinal and flavoring properties of several herbs. Herbs are traditionally used for the treatment and prevention of ailments such as stomach pain, headache, diabetes, hypertension, rheumatism, and many others [4]. The hyperarid environment of the UAE hosts a diverse range of medicinal plants. According to a recent study on the diversity and conservation status of plants in the UAE, $18 \%$ of the plant species were found to possess medicinal properties [4]. A survey on the herbal remedies used in Abu Dhabi has found 65 different herbs used to treat 48 conditions [5].

In parallel with the increasing interest in the therapeutic benefits of herbal products, there has been an increasing concern over the safety and toxicity of natural herbs and formulations available on the market. There is a widespread misconception that natural herbs and plants are inherently safe; nevertheless, there has been a large volume of reports on incidences of toxicity and adverse effects linked to the use of herbal plants and their formulations in different parts of the world [6]. In a survey on herbal remedies used in the UAE, the majority of respondents felt they were safe; however, 27 people reported adverse health effects [5]. The toxicity of herbal plants may be related to contaminants such as pesticides, microbes, heavy metals, chemical toxins, and adulterants [7]. In general, the geography, the geochemical soil characteristics, contaminants in the soil, water, and air, and other growth, transport, and storage conditions can significantly affect the properties and the quality of the herbal plants and their formulations [7]. 
The toxicity of trace metals on human health and the environment has attracted considerable attention in recent years. Plants are the main link in the transfer of heavy metals from the contaminated soil to humans. Heavy metals have a tendency to accumulate in the food chain. Heavy metals have low excretion rates through the kidney which could result in damaging effects on humans even at very low concentrations. Metals such as zinc, copper, iron, manganese, and chromium are essential nutrients; they are important for the physiological and biological functions of the human body. However, an increase in their intake above certain permissible limits can become toxic $[8,9]$. In general, a number of health problems were linked to excessive uptake of dietary heavy metals including a decrease in immunological defenses, cardiac dysfunction, fetal malformation, impaired psychosocial and neurological behavior, gastrointestinal cancer, and many others $[10,11]$. The heavy metal contamination of herbal remedies has been reported earlier in several Asian, South American, and African herbal products in different countries [12-16].

There is very little information available on the safety of traditional herbs and their products sold in the UAE market. This study aims at determining the level of heavy metal contamination in some commonly consumed herbs to assess their relative safety and potential health risks based on the World Health Organization (WHO) standard limits.

\section{Materials and Methods}

A total of eighty-one herb samples both local and imported (fresh and dried) of seven different types of herbs were purchased from 13 different sources in the local markets of Dubai. The herb samples used in this study were purchased from authenticated shops/supermarkets approved by Dubai municipality. Table 1 shows a list of the herbs common and scientific names and the number of samples analyzed. Fresh samples were air-dried at room temperature. All samples were powdered, sieved, and stored in plastic bags for metal analysis.

All glassware and digestion vessels were soaked in 20\% nitric acid and rinsed with ultrapure water (Millipore Elix Advantage Water Purification System, Millipore, MA, USA). Multielement standard solutions of lead $(\mathrm{Pb})$, cadmium $(\mathrm{Cd})$, iron $(\mathrm{Fe})$, zinc $(\mathrm{Zn})$, and copper $(\mathrm{Cu})$ were prepared by dilution of $1000 \mathrm{mg} / \mathrm{L}$ stock solutions (Fluka TraceCert Ultra, Sigma-Aldrich) with $5 \%$ nitric acid $\left(\mathrm{HNO}_{3}\right)$ solution. The calibration curve for each element was linear and a correlation coefficient of 0.995 was obtained.

For microwave digestion, $0.5 \mathrm{~g}$ of the herb sample was accurately weighed into a digestion vessel (MARSXpress), followed by addition of $0.5 \mathrm{~mL}$ of $37 \%$ hydrochloric acid $(\mathrm{HCl})$ (trace metal concentrated, Suprapur, Merk), $9.0 \mathrm{~mL}$ of $69 \%$ nitric acid $\left(\mathrm{HNO}_{3}\right)$ (trace metal concentrated, Suprapur, Merk), and $1 \mathrm{~mL}$ of $30 \%$ hydrogen peroxide $\left(\mathrm{H}_{2} \mathrm{O}_{2}\right)$ (Sigma-Aldrich). The mixture was subjected to US-EPA 3052 microwave-assisted digestion in MARS Microwave digestion system (CEM Corporation, Matthews, USA) [17]. At the end of the digestion program, the samples were filtered
TABLE 1: Herbs common name and scientific name and the number of collected samples.

\begin{tabular}{lcc}
\hline Common name & Scientific name & $\begin{array}{c}\text { Total number of } \\
\text { samples collected } \\
(N=81)\end{array}$ \\
\hline Parsley & Petroselinum crispum & 13 \\
Basil & Ocimum basilicum & 11 \\
Sage & Salvia officinalis & 11 \\
Oregano & Origanum vulgare & 11 \\
Mint & Mentha spicata & 13 \\
Thyme & Thymus vulgaris & 13 \\
Chamomile & Matricaria chamomilla & 9 \\
\hline
\end{tabular}

and quantitatively transferred to $25 \mathrm{~mL}$ volumetric flask and diluted with $0.2 \%$ nitric acid solution. The concentration of metals in the sample was determined using atomic absorption spectrophotometer (AA240FS series by Varian Australia Pty Ltd.).

All quality control and assurance measures were taken including calibration check measures, determination of Method Quantification Limits (MQL), and replicate analysis of samples. Concentration of heavy metals is expressed as the mean value $\left(\mathrm{mg} \cdot \mathrm{kg}^{-1}\right)$ of dry weight \pm SD of three subsamples collected from the same source.

\section{Results and Discussion}

The results of heavy metals analysis in the selected samples are presented in Table 2.

3.1. Cadmium. The cadmium (Cd) concentration varied from less than 0.1 to $1.11 \mathrm{mg} \cdot \mathrm{kg}^{-1}$. Cadmium was not detected in any of the thirteen mint samples. The maximum concentrations of $\mathrm{Cd}$ detected in parsley, chamomile, basil, sage, oregano, and thyme were $0.21,0.82,1.11,0.88,0.35$, and $0.63 \mathrm{mg} \cdot \mathrm{kg}^{-1}$, respectively.

Overall, among the 78 herb samples analyzed for cadmium, $29 \%$ of the samples contained high levels of cadmium exceeding $0.3 \mathrm{mg} \cdot \mathrm{kg}^{-1}$, the permissible limit (PL) set by $\mathrm{FAO} / \mathrm{WHO}$ for medicinal herbs and plants in different countries $[18,19]$. The cadmium levels in all mint and parsley samples were below the permissible limit (PL). 55\%, 80\%, $66 \%, 9 \%$, and $27 \%$ of chamomile, basil, sage, oregano, and thyme samples, respectively, exceeded the permissible limits (PL) for cadmium in medicinal herbs and plants. Similar results of high levels of cadmium in Egyptian and Iranian medicinal herbs and plants have been reported in earlier studies $[20,21]$.

The high levels of cadmium possess a serious toxicological effect on human health. Kidney is the critical target organ in the exposed population. Excretion of cadmium is very slow and it accumulates in human kidney for a relatively long time, resulting in an irreversible impairment of the renal tract [22-24]. At high concentrations, cadmium produces serious effects on the liver and vascular and immune system [24]. 


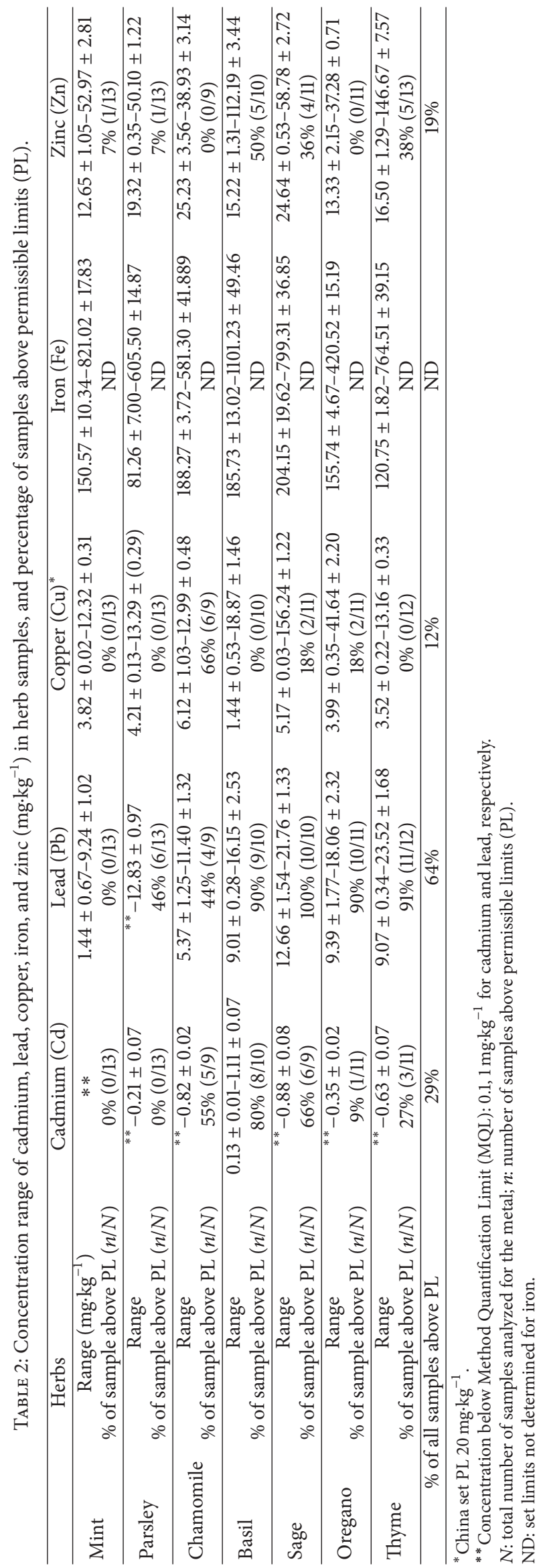


3.2. Lead. The content of lead $(\mathrm{Pb})$ in the analyzed samples ranged from less than 1.0 to $23.52 \mathrm{mg} \cdot \mathrm{kg}^{-1}$. The maximum concentrations of lead in mint, parsley, chamomile, basil, sage, oregano, and thyme were found to be $9.24,12.83,11.40$, $16.15,21.76,18.06$, and $23.52 \mathrm{mg} \cdot \mathrm{kg}^{-1}$, respectively.

The FAO/WHO maximum permissible limit of lead in consumed medicinal herbs is $10 \mathrm{mg} \cdot \mathrm{kg}^{-1}[18,19]$. The obtained results showed that $64 \%$ of the analyzed samples exceeded this limit. The levels of lead in all mint samples were below the permissible limits (PL) and ranged between 1.44 and $9.24 \mathrm{mg} \cdot \mathrm{kg}^{-1}$. However, 46\%, 44\%, 90\%, 100\%, 90\%, and $91 \%$ of parsley, chamomile, basil, sage, oregano, and thyme, respectively, showed concentrations of lead higher than $10 \mathrm{mg} \cdot \mathrm{kg}^{-1}$.

High concentration of lead above permissible limits in medicinal plants and herbs has been reported in other Middle Eastern countries. The mean lead concentration in most commonly and commonly used medicinal herbs in Jordan was found to be 13.9 and $13.1 \mathrm{mg} / \mathrm{kg}$ on a dry weight basis, respectively [23]. Maximum levels of $14.4 \mathrm{mg} / \mathrm{kg}$ and 21.7 of lead were also reported in Egyptian and Iranian spices and medicinal plants, respectively [20,21].

Lead is known to be one of the highly toxic environmental pollutants. It can complex with various biomolecules and adversely affect their functions. Lead exposure may have an adverse effect on the blood, nervous, immune, renal, skeletal, muscular, reproductive, and cardiovascular systems causing poor muscle coordination, gastrointestinal symptoms, brain and kidneys damage, hearing and vision impairments, and reproductive defects $[25,26]$. Exposures to lead at early childhood and prenatally are associated with slowed cognitive development, learning deficits, and many other effects [25, 26].

3.3. Copper. The copper $(\mathrm{Cu})$ concentrations varied in a wide range between 1.44 and $156.24 \mathrm{mg} \cdot \mathrm{kg}^{-1}$. The maximum concentrations of copper in mint, parsley, chamomile, basil, sage, oregano, and thyme were 12.32, 13.29, 12.99, 18.87, 156.24, 41.64 , and $13.16 \mathrm{mg} \cdot \mathrm{kg}^{-1}$, respectively.

The regulatory limits of the WHO/FAO have not been established yet for the copper in herbal medicines [27]. China and Singapore had set limits for copper in medicinal plants at 20 and $150 \mathrm{mg} \cdot \mathrm{kg}^{-1}$, respectively [27]. In this study, only $12 \%$ of the samples exceeded the Chinese limit of $20 \mathrm{mg} \cdot \mathrm{kg}^{-1}$, where one sage sample showed a value above $150 \mathrm{mg} \cdot \mathrm{kg}^{-1}$ limit of Singapore. $66 \%$ of the chamomile samples and $18 \%$ of each of the sage and oregano samples exceeded $20 \mathrm{mg} \cdot \mathrm{kg}^{-1}$.

Copper is an essential component of many enzymes, therefore playing a significant role in a wide range of physiological processes including iron utilization, free radicals elimination, bone and connective tissues development, melanin production, and many others. Nevertheless, excessive intake of copper can cause dermatitis, irritation of the upper respiratory tract, abdominal pain, nausea, diarrhea, vomiting, and liver damage [23, 27].
3.4. Zinc. The concentration of zinc $(\mathrm{Zn})$ in the analyzed samples ranged between 12.65 and $146.67 \mathrm{mg} \cdot \mathrm{kg}^{-1}$. The maximum concentrations of zinc in mint, parsley, chamomile, basil, sage, oregano, and thyme were 52.97, 50.10, 38.93, 112.19, $58.78,37.28$, and 146.67 , respectively. Overall, results revealed that only $19 \%$ of the samples analyzed had concentrations higher than $50 \mathrm{mg} \cdot \mathrm{kg}^{-1}$, the $\mathrm{FAO} / \mathrm{WHO}$ permissible limit (PL) set for zinc in herbal medicines $[18,19]$. Out of the seven different herbs analyzed, $7 \%$ of each of mint and parsley samples, $36 \%$ of sage, and $50 \%$ of basil samples exceeded the permissible limits for zinc.

Zinc is an essential trace element necessary for proper growth, blood clotting, thyroid function, and protein and DNA synthesis. Little information is available on $\mathrm{Zn}$ toxicity; however, high zinc intake beyond permissible limits produces toxic effects on the immune system, blood lipoprotein levels, and copper level [28].

3.5. Iron. The observed range of iron $(\mathrm{Fe})$ in the current study was found between 81.25 and $1101.22 \mathrm{mg} \cdot \mathrm{kg}^{-1}$. The maximum concentrations of iron in mint, parsley, chamomile, basil, sage, oregano, and thyme were 821.01, 605.50, 581.30, 1101.23, $799.31,420.52$, and $764.51 \mathrm{mg} \cdot \mathrm{kg}^{-1}$, respectively.

The WHO limit for iron in medicinal herbs has not been established yet. The results of the current study show a wide variation of iron in different herb samples. These results are comparable to values of iron found in Egyptian spices and medicinal plants that ranged between 26.96 and $1046.25 \mathrm{mg} \cdot \mathrm{kg}^{-1}[20]$.

Iron has several key functions in the human body including oxygen supply, energy production, and immunity. Iron overdose is associated with symptoms of dizziness, nausea and vomiting, diarrhea, joints pain, shock, and liver damage. Iron toxicity has an adverse effect on various metabolic functions and cardiovascular system [23].

Overall the results of analysis showed that heavy metals were present in varied concentrations in the seven traditional herbs commonly consumed in the UAE. The concentration of heavy metals in many cases exceeded the internationally accepted permissible levels. The wide variations in metal concentrations in the analyzed herbs could be attributed to differences in the plant metal uptake and translocation capabilities. Metal uptake by plants depends on several factors including the plant species and their stage of growth, the soil type, and the type of metals absorbed $[29,30]$. Studies have shown wide variations in concentration factor of different metals among different plant species and sampling sites. For example, high transfer values of cadmium, copper, and nickel from soils irrigated with wastewater to food crops were observed, indicating a stronger accumulation of these metals by the food crops compared to other metals [31]. Studies have also shown that plants do not accumulate lead. The concentration of lead in plants was found to be more correlated to the level of lead in the atmosphere [29, 31]. Another study that monitored the metallic micronutrients and heavy metals in herbs, spices, and medicinal plants from Austria has found that species such as St. John's wort, poppy, yarrow, chamomile, and absinth have higher tendency to accumulate 
cadmium. Similarly, results of this study have shown higher cadmium levels in chamomile, in addition to basil and sage [32]. The bioavailability of metals is influenced by several factors among which are the soil $\mathrm{pH}$, the metal levels in the soil, the oxidation reduction potential of the soil, and other chemical and physical factors $[29,30]$. Furthermore, contamination could occur during storage and/or at the point of sale. A study was conducted in India to compare the heavy metals concentration in different Berberis species collected from their natural habitats and their market samples. Results have shown that market samples were more contaminated with heavy metals than natural samples [33]. In general, herbs can be contaminated during growing, harvesting, and processing. Sources of heavy metal contamination in herbs could be linked to water used in irrigation, polluted soils, fertilizers and pesticides, industrial emissions, transportation, and harvesting and storage processes. The health risk due to metal contamination, in general, depends on the average daily dietary intake.

\section{Conclusion}

In conclusion, the results of this study indicate a potential health risk of heavy metals to consumers in the UAE over long-term consumption of contaminated herbs. The findings of this study also highlight the significance of safety and hygiene practices and measures starting from the harvest area of the herbs until they reach the consumer end. It is evident that there is an urgent need to implement a regular monitoring and testing program on the quality of the local and imported herbs sold in the UAE market. Further studies are required to determine the presence of toxic metals and to assess their long-term cumulative risk on consumer health.

\section{Conflict of Interests}

The authors declare that there is no conflict of interests regarding the publication of this paper.

\section{Acknowledgment}

The authors would like to thank the College of Sustainability Sciences and Humanities at Zayed University for funding this study.

\section{References}

[1] D. S. Fabricant and N. R. Farnsworth, "The value of plants used in traditional medicine for drug discovery," Environmental Health Perspectives, vol. 109, no. 1, pp. 69-75, 2001.

[2] N. Sahoo, P. Manchikanti, and S. Dey, "Herbal drugs: standards and regulation," Fitoterapia, vol. 81, no. 6, pp. 462-471, 2010.

[3] World Health Organization (WHO), Traditional Medicine Strategy (2002-2005), World Health Organization, Geneva, Switzerland, 2002.

[4] S. Sakkir, M. Kabshawi, and M. Mehairbi, "Medicinal plants diversity and their conservation status in the United Arab Emirates (UAE)," Journal of Medicinal Plants Research, vol. 6, no. 7, pp. 1304-1322, 2012.
[5] F. A. AlBraik, P. M. Rutter, and D. Brown, "A cross-sectional survey of herbal remedy taking by United Arab Emirate (UAE) citizens in Abu Dhabi," Pharmacoepidemiology and Drug Safety, vol. 17, no. 7, pp. 725-732, 2008.

[6] E. Ernst, "Toxic heavy metals and undeclared drugs in Asian herbal medicines," Trends in Pharmacological Sciences, vol. 23, no. 3, pp. 136-139, 2002.

[7] B. Saad, H. Azaizeh, G. Abu-Hijleh, and O. Said, "Safety of traditional Arab herbal medicine," Evidence-Based Complementary and Alternative Medicine, vol. 3, no. 4, pp. 433-439, 2006.

[8] S. I. Korfali, T. Hawi, and M. Mroueh, "Evaluation of heavy metals content in dietary supplements in Lebanon," Chemistry Central Journal, vol. 7, no. 1, article 10, 2013.

[9] S. I. Korfali, M. Mroueh, M. Al-Zein, and R. Salem, "Metal concentration in commonly used medicinal herbs and infusion by Lebanese population: health impact," Journal of Food Research, vol. 2, no. 2, pp. 70-80, 2013.

[10] L. Mahan, S. Escott-Stump, and L. Raymond, Krause's Food and Nutrition Care Process, edited by: Y. Alexopoulos, Saunders, St. Louis, Mo, USA, 13th edition, 2012.

[11] R. Singh, N. Gautam, A. Mishra, and R. Gupta, "Heavy metals and living systems: an overview," Indian Journal of Pharmacology, vol. 43, no. 3, pp. 246-253, 2011.

[12] M. Rahimi, R. Farhadi, and M. Balashahri, "Effects of heavy metals on the medicinal plant," International Journal of Agronomy and Plant Production, vol. 3, no. 4, pp. 154-158, 2012.

[13] R. B. Saper, S. N. Kales, J. Paquin et al., "Heavy metal content of Ayurvedic herbal medicine products," Journal of the American Medical Association, vol. 292, no. 23, pp. 2868-2873, 2004.

[14] E. S. J. Harris, S. Cao, B. A. Littlefield et al., "Heavy metal and pesticide content in commonly prescribed individual raw Chinese Herbal Medicines," Science of the Total Environment, vol. 409, no. 20, pp. 4297-4305, 2011.

[15] M. Saeed, N. Muhammad, and H. Khan, "Assessment of heavy metal content of branded Pakistani herbal products," Tropical Journal of Pharmaceutical Research, vol. 10, no. 4, pp. 499-506, 2011.

[16] S. S. Alwakeel, "Microbial and heavy metals contamination of herbal medicines," Research Journal of Microbiology, vol. 3, no. 12, pp. 683-691, 2008.

[17] US Environmental Protection Agency, "Microwave assisted acid digestion of siliceous and organically based matrices," EPA Method 3052, 1996.

[18] World Health Organization, WHO Guidelines for Assessing Quality of Herbal Medicines with Reference to Contaminants and Residues, World Health Organization, Geneva, Switzerland, 2006.

[19] World Health Organization (WHO), Quality Control Methods for Medicinal Plant Materials, World Health Organization, Geneva, Switzerland, 2005.

[20] A. A. K. Abou-Arab and M. A. Abou Donia, "Heavy metals in egyptian spices and medicinal plants and the effect of processing on their levels," Journal of Agricultural and Food Chemistry, vol. 48, no. 6, pp. 2300-2304, 2000.

[21] P. Ziarati, "Determination of contaminants in some Iranian popular herbal medicines," Journal of Environmental \& Analytical Toxicology, vol. 2, no. 1, pp. 1-3, 2012.

[22] S.-M. Li, Y. Fang, H.-M. Ning, and Y. X. Wu, "Heavy metals in Chinese therapeutic foods and herbs," Journal of the Chemical Society of Pakistan, vol. 34, no. 5, pp. 1091-1095, 2012. 
[23] S. Martin and W. Griswold, "Human health effects of heavy metals," in Environmental Science and Technology Briefs for Citizens, vol. 15, pp. 1-6, Center for Hazardous Substance Research, Manhattan, Kan, USA, 2009.

[24] M. A. G. Maobe, E. Gatebe, L. Gitu, and H. Rotich, "Profile of heavy metals in selected medicinal plants used for the treatment of diabetes, malaria and pneumonia in Kisii Region southwest Kenya," Global Journal of Pharmacology, vol. 6, no. 3, pp. 245251, 2012.

[25] F. M. Johnson, "The genetic effects of environmental lead," Mutation Research-Reviews in Mutation Research, vol. 410, no. 2, pp. 123-140, 1998.

[26] Agency for Toxic Substances and Disease Registry (ATSDR), Toxicological Profile for Lead (Update), Public Health Service, U.S. Department of Health and Human Services, Atlanta, Ga, USA, 2007.

[27] R. Ulla, J. A. Khader, I. Hussain, N. M. AbdElsalam, M. Talha, and N. Khan, "Investigation of macro and micro-nutrients in selected medicinal plants," African Journal of Pharmacy and Pharmacology, vol. 6, no. 25, pp. 1829-1832, 2012.

[28] G. J. Fosmire, "Zinc toxicity," American Journal of Clinical Nutrition, vol. 51, no. 2, pp. 225-227, 1990.

[29] O. E. Orisakwe, J. K. Nduka, C. N. Amadi, D. Dike, and O. O. Obialor, "Evaluation of potential dietary toxicity of heavy metals of vegetables," Journal of Environmental \& Analytical Toxicology, vol. 2, no. 3, pp. 136-139, 2012.

[30] P. Verma, K. V. George, H. V. Singh, and R. N. Singh, "Modeling cadmium accumulation in radish, carrot, spinach and cabbage," Applied Mathematical Modelling, vol. 31, no. 8, pp. 1652-1661, 2007.

[31] C. S. Khan, Q. Cao, Y. M. Zheng, Y. Z. Huang, and Y. G. Zhu, "Health risks of heavy metals in contaminated soils and food crops irrigated with wastewater in Beijing, China," Environmental Pollution, vol. 152, no. 3, pp. 686-692, 2008.

[32] R. Chizzola, H. Michitsch, and C. Franz, "Monitoring of metallic micronutrients and heavy metals in herbs, spices and medicinal plants from Austria," European Food Research and Technology, vol. 216, no. 5, pp. 407-411, 2003.

[33] S. K. Srivastava, V. Rai, M. Srivastava, A. K. S. Rawat, and S. Mehrotra, "Estimation of heavy metals in different Berberis species and its market samples," Environmental Monitoring and Assessment, vol. 116, no. 1-3, pp. 315-320, 2006. 


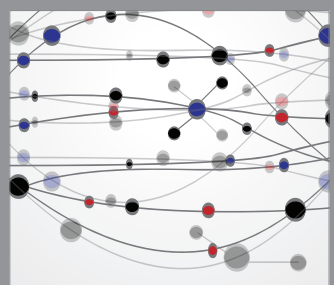

The Scientific World Journal
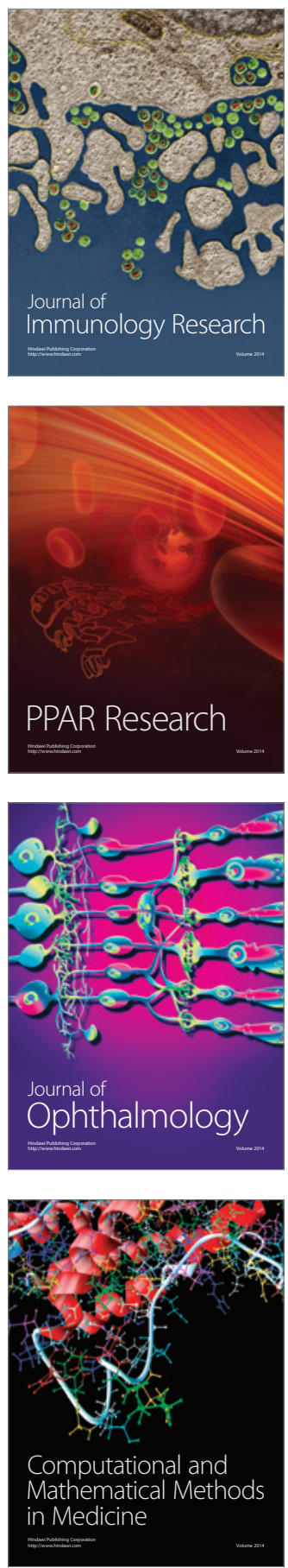

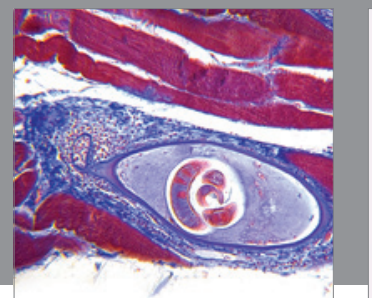

Gastroenterology

Research and Practice
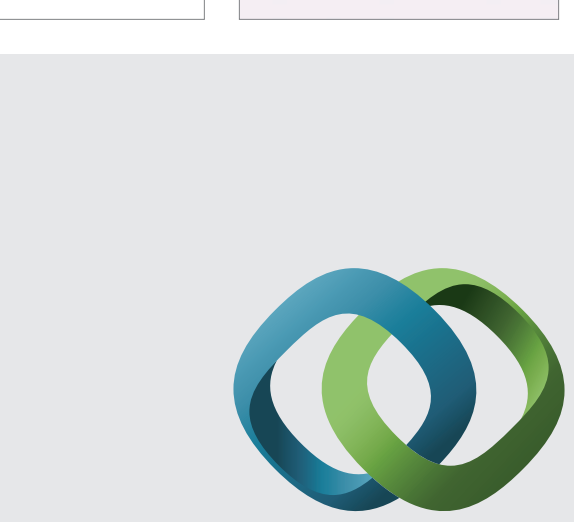

\section{Hindawi}

Submit your manuscripts at

http://www.hindawi.com
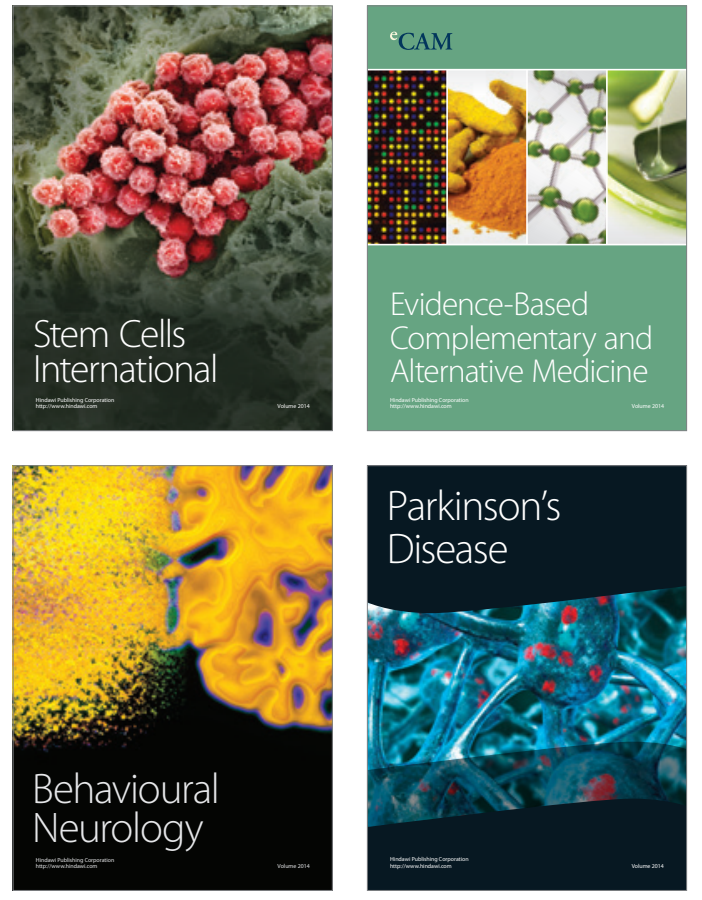
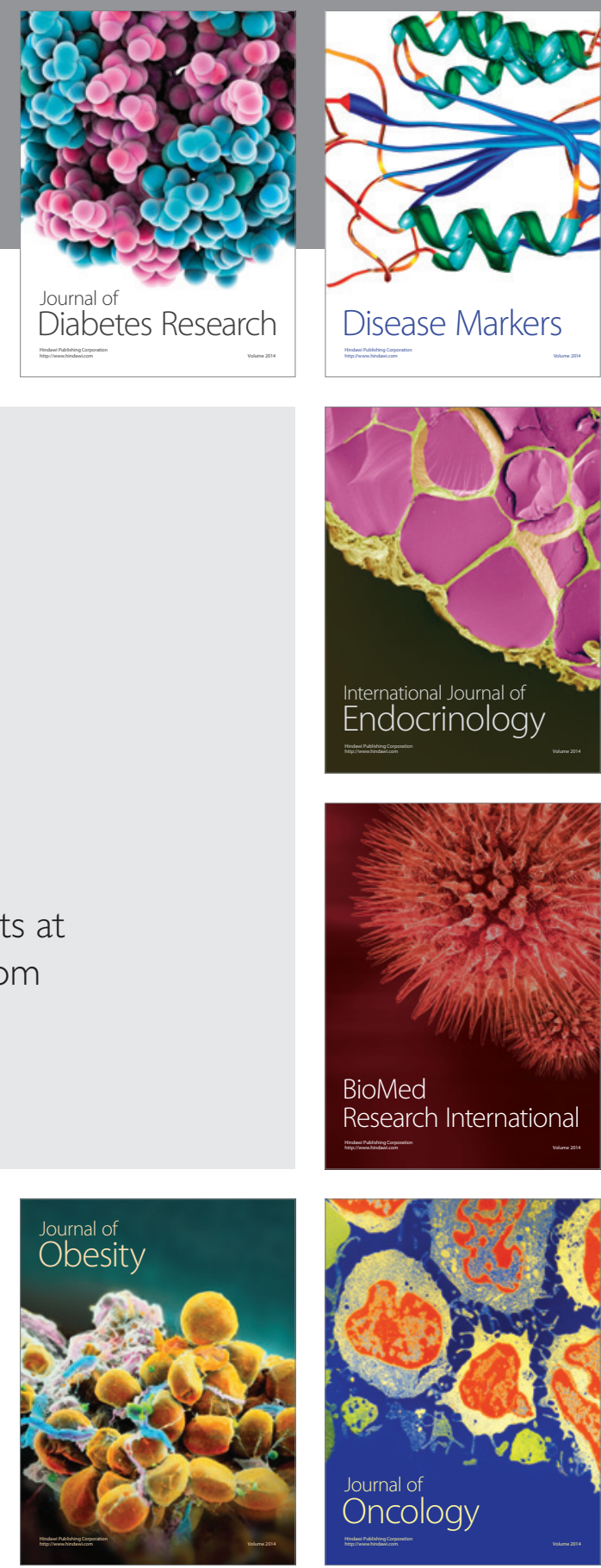

Disease Markers
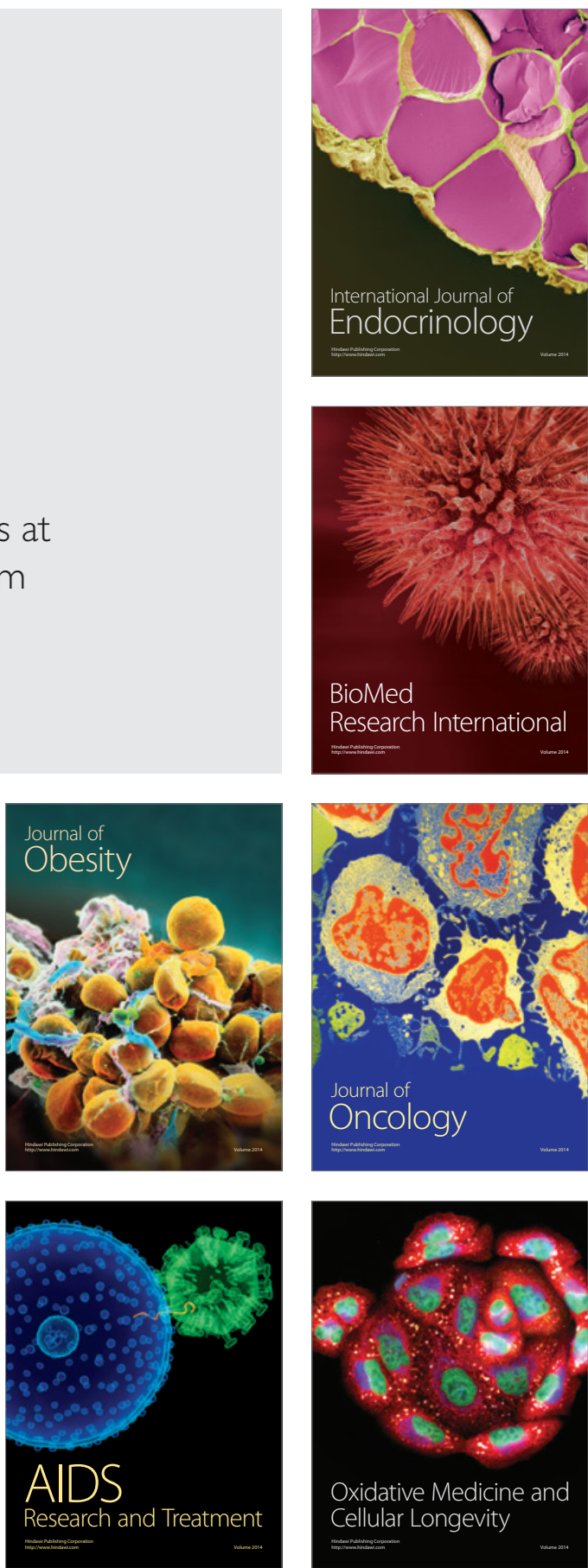